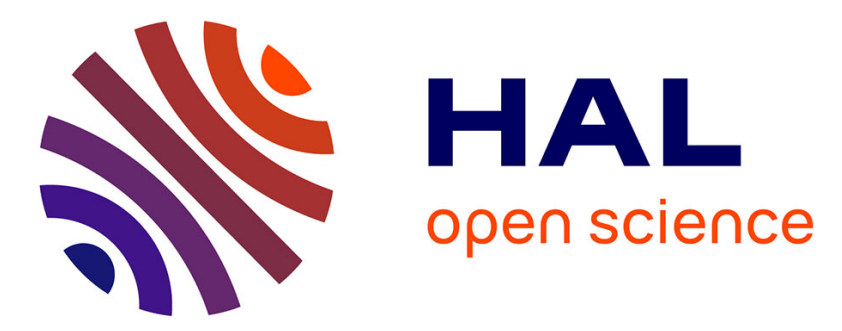

\title{
Focal distribution of diflubenzuron resistance mutations in Culex pipiens mosquitoes from Northern Italy
}

R Porretta, R Fotakis, R Mastrantonio, R Chaskopoulou, M Michaelakis, I. Kioulos, Mylène Weill, S. Urbanelli, J. Vontas, R. Bellini

\section{- To cite this version:}

R Porretta, R Fotakis, R Mastrantonio, R Chaskopoulou, M Michaelakis, et al.. Focal distribution of diflubenzuron resistance mutations in Culex pipiens mosquitoes from Northern Italy. Acta Tropica, 2019, 193, pp.106-112. 10.1016/j.actatropica.2019.02.024 · hal-02114323

\section{HAL Id: hal-02114323 \\ https://hal.science/hal-02114323}

Submitted on 30 Nov 2019

HAL is a multi-disciplinary open access archive for the deposit and dissemination of scientific research documents, whether they are published or not. The documents may come from teaching and research institutions in France or abroad, or from public or private research centers.
L'archive ouverte pluridisciplinaire HAL, est destinée au dépôt et à la diffusion de documents scientifiques de niveau recherche, publiés ou non, émanant des établissements d'enseignement et de recherche français ou étrangers, des laboratoires publics ou privés.

\section{(1) (1) $\$$}

Distributed under a Creative Commons Attribution - NonCommercial - NoDerivatives| 4.0 


\section{Accepted Manuscript}

Title: Focal distribution of diflubenzuron resistance mutations in Culex pipiens mosquitoes from Northern Italy

Authors: D. Porretta, E.A. Fotakis, V. Mastrantonio, A. Chaskopoulou, A. Michaelakis, I. Kioulos, M. Weill, S. Urbanelli, J. Vontas, R. Bellini

PII: S0001-706X(18)31634-6

DOI: $\quad$ https://doi.org/10.1016/j.actatropica.2019.02.024

Reference: $\quad$ ACTROP 4938

To appear in: $\quad$ Acta Tropica

Received date: $\quad 21$ December 2018

Revised date: $\quad 19$ February 2019

Accepted date: $\quad 22$ February 2019

Please cite this article as: Porretta D, Fotakis EA, Mastrantonio V, Chaskopoulou A, Michaelakis A, Kioulos I, Weill M, Urbanelli S, Vontas J, Bellini R, Focal distribution of diflubenzuron resistance mutations in Culex pipiens mosquitoes from Northern Italy, Acta Tropica (2019), https://doi.org/10.1016/j.actatropica.2019.02.024

This is a PDF file of an unedited manuscript that has been accepted for publication. As a service to our customers we are providing this early version of the manuscript. The manuscript will undergo copyediting, typesetting, and review of the resulting proof before it is published in its final form. Please note that during the production process errors may be discovered which could affect the content, and all legal disclaimers that apply to the journal pertain. 


\section{Focal distribution of diflubenzuron resistance mutations in Culex}

\section{pipiens mosquitoes from Northern Italy}

Porretta $^{1}{ }^{1}$, EA Fotakis ${ }^{2,3}$, V Mastrantonio ${ }^{1}$, A Chaskopoulou ${ }^{4}$, A Michaelakis ${ }^{5}$, I

Kioulos $^{2}$, M Weill ${ }^{6}, \mathrm{~S}_{\text {Urbanelli }}{ }^{1}, \mathrm{~J}_{\text {Vontas }}{ }^{2,3}$ and R Bellini $^{7}$

${ }^{1}$ Department of Environmental Biology, Sapienza University of Rome, Rome, Italy

${ }^{2}$ Department of Crop Science, Pesticide Science Lab, Agricultural University of

Athens, Athens, Greece

${ }^{3}$ Institute of Molecular Biology and Biotechnology, Foundation for Research and

Technology Hellas, Heraklion, Crete, Greece

${ }^{4}$ European Biological Control Laboratory, USDA-ARS, Thessaloniki, Greece

${ }^{5}$ Laboratory of Agricultural Entomology, Department of Entomology and

Agricultural Zoology, Benaki Phytopathological Institute, Kifissia, Attica, Greece

${ }^{6}$ Institut des Sciences de l'Evolution (CNRS-Université de Montpellier-IRD-EPHE),

34095 Montpellier, CEDEX 5, France

${ }^{7}$ Medical and Veterinary ntomology, Centro Agricoltura Ambiente "G. Nicoli",

Bologna, Italy

* Corresponding author:

Sandra Urbanelli

Department of Environmental Biology, Sapienza University of Rome, Rome, Italy.

Email: sandra.urbanelli@uniroma1.it 


\section{Graphical abstract}

Frequency of the diflubenzuron (DFB) susceptible and resistant alleles found in the Emilia-Romagna provinces (Italy) associated with DFB pressures from mosquito and orchard pest controls.

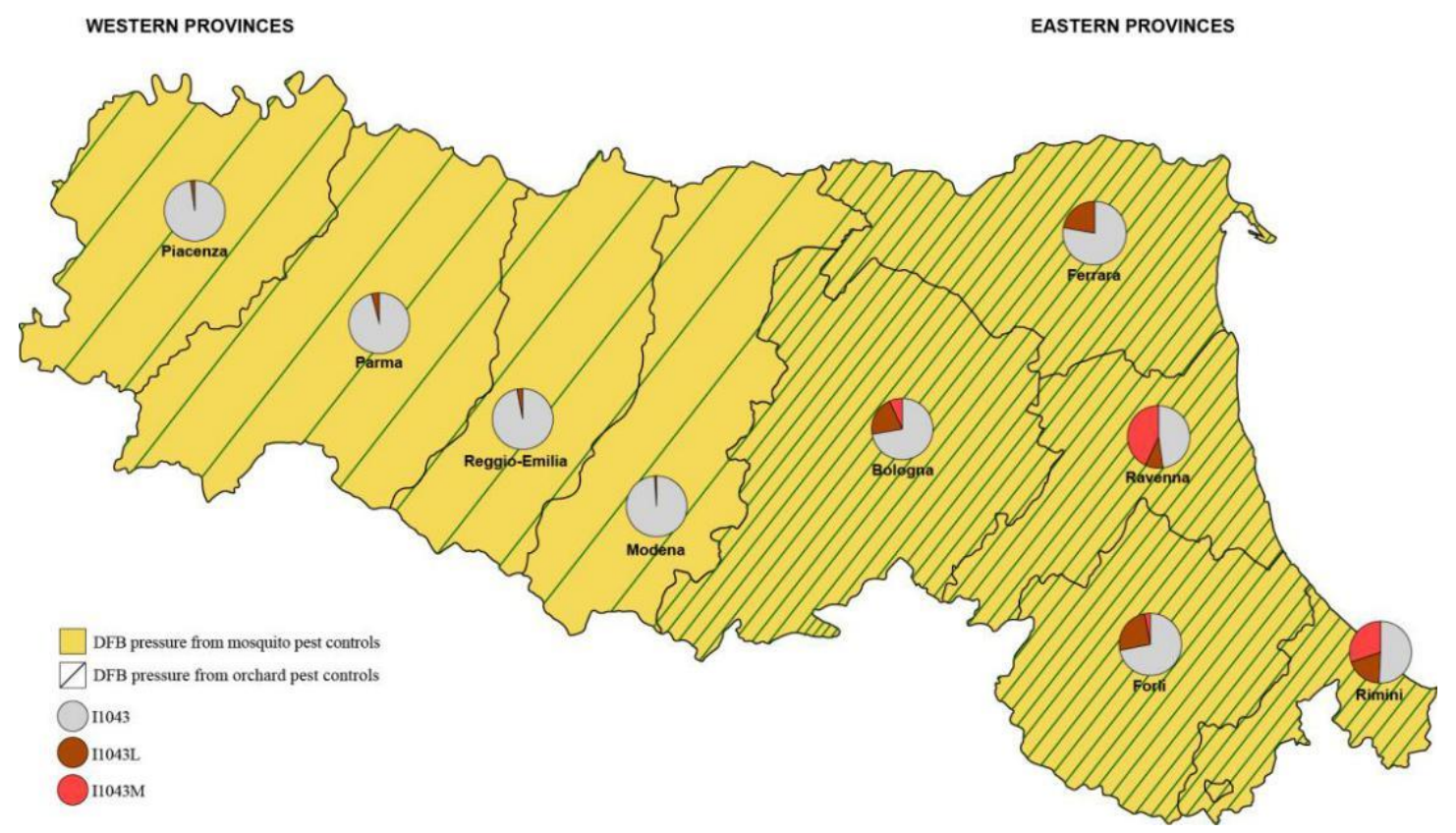

\section{ACCEPTEDHighlights}

- Diflubenzuron resistant mutations occur in Italian populations of Culex pipiens, reaching over $70 \%$

- Resistant allele frequencies increased from West to East of Emilia-Romagna region

- he intense insecticide pressure due to past agricultural applications, along with current mosquito control, can account for the observed pattern of focal resistance

- Ongoing $C x$. pipiens resistance surveillance is of utmost importance to prevent its diffusion 


\section{Abstract}

Insecticide resistance is a major threat for vector control and prevention of mosquito borne diseases. In the Culex pipiens mosquitoes, resistance against diflubenzuron (DFB) was firstly detected in Ravenna (Emilia-Romagna region, Northern Italy), in 2015. The resistant phenotypes were associated with two mutations, I1043M and I1043L, at the amino acid 1043 of the chitin synthase gene. In this study, we monitored the presence, frequency and geographical distribution of the DFB resistant mutations in $C x$. pipiens populations from Northern Italy, and in populations from Greece and France. In the Emilia-Romagna region, the resistant mutations were detected in 20 out of the 30 populations analysed, reaching allelic frequencies over 70\%. The presence and distribution of the resistance mutations was highly focal, with a clear pattern of increasing resistant allelic frequencies moving from the Western towards the Eastern provinces of Emilia-Romagna. Contrary to Italy, DFB resistant alleles were not detected in the $C x$. pipiens mosquitoes sampled from Greece and France. Following statistical, literature and bibliographical database analyses on the history of DFB insecticide use in the study areas, we suggest that the selection pressures from the intense agricultural DFB applications occurring throughout the '80-'90s against orchard pests, followed, from 2000s onwards by mosquito control DFB applications, may account for the high mutation frequencies observed in the $C x$. pipiens populations of the Eastern provinces of Emilia-Romagna. The findings are of major concern for public health in Italy and Europe, as DFB remains a very important insecticide used for controlling arbovirus mosquito vectors, where alternative larvicides are extremely limited. 
Keywords: insecticide resistance; vector control; agriculture pest control; insect growth regulators; chitin synthase.

\section{Introduction}

Over the last decade, Southern European countries have witnessed a resurgence of vector borne diseases with Italy and Greece reporting a series of West Nile Virus (WNV) outbreaks (Chaskopoulou et al. 2011; Paz and Semenza 2013; WHO 2014; Mavridis et al. 2018).

In the summer of 2018, a WNV outbreak unraveled in both countries with reported 569 cases in Italy, 309 cases in Greece, and a total of 45 and 42 deaths respectively (until $8^{\text {th }}$ November, 2018). France, a country least affected by previous human WNV outbreaks, in 2018 reported a total of 24 cases (until $8^{\text {th }}$ November, 2018) compared to 1 case in 2017 (ECDC 2017, 2018).

$C x$. pipiens mosquitoes are among the most abundant mosquito species in Southern Europe, displaying a widespread distribution in natural, agricultural and urban settings, and they are the main vectors of WNV (Gomes et al. 2013; WHO 2014; Fotakis et al. 2017; Möhlmann et al. 2017). Further, WNV strains associated with previous WNV outbreaks and human clinical cases have been detected in $C x$. pipiens mosquitoes collected from disease transmission areas in Greece and Italy, prior to, during and following the outbreaks (Chaskopoulou et al. 2013; Rizzo et al. 2016; Mavridis et al. 2018). In France, members of the Cx. pipiens complex have been associated with WNV outbreaks in horses (Balenghien et al. 2008;

haskopoulou et al. 2016).

Prevention of mosquito borne diseases and the nuisance caused by mosquitoes largely relies on chemical control (Becker et al. 2010). Larviciding, although reliant on a very limited number of public health insecticides, is an indispensable tool for $C x$. pipiens control. In Europe, under the current EU Biocide policy, larval control relies 
on Bacilus thuringiensis israelensis (B.t.i.), Lysinibacillus sphaericus (L.s.), Methoprene, Pyriproxyfen and Diflubenzuron (DFB) (Bellini et al. 2014; Becker and Lüthy 2017).

DFB is abenzoylurea (BFU) insecticide that interferes with the synthesis of chitin, causing abortive molting and other alterations in the physiology of the insect (Merzendofer 2013). Its mechanism of action has been recently clarified and involves the interaction of the insecticide with the chitin synthase 1 (CHS1) enzyme, responsible for chitin synthesis in the insect cuticle (Douris et al. 2016). DFB has been used extensively in agriculture and forestry against insect pest larvae, in public health against mosquitoe larvae and as a veterinary drug for the treatment of sea lice infestations in Atlantic salmon (Rath et al. 2016).

A major problem associated with the limited selection of available insecticides and their extensive use in mosquito and agricultural pest control is the development of insecticide resistance (Nkya et al. 2013; Feyereisen et al. 2015; Liu 2015). In insect crop pests, resistance to DFB was detected in the 1990s in the codling moth Cydia pomonella L. in northern Italy (Trentino Alto Adige region and Bologna province in the Emilia-Romagna Region), France, Switzerland and Spain (Waldner 1993; Ioratti et al. 2000; Reyes et al. 2007). Likewise, in the leaf miner Leucoptera malifoliella, a loss of efficacy of DFB was reported in apple orchards in the province of Bologna, Italy, in 1986-1988 (Faccioli et al. 1990). Mixed-function oxidase (MFO) activities were positively correlated with resistance to DFB in C. pomonella, whereas the use of pyperonylbutoxide improved the efficacy of DFB in L. malifoliella, suggesting a major role of detoxification systems in the resistant phenotypes (Faccioli et al. 1990; Ioratti et al. 2000).

In mosquitoes, DFB resistance was detected for the first time in Cx. pipiens sampled from Ravenna (Italy), in 2015. The resistant phenotypes were associated with 
two mutations, I1043M and I1043L, at the amino acid 1043 of the chitin synthase gene (chs) (Grigoraki et al. 2017). Functional characterization of the mutations in the Drosophila melanogaster chs gene with the genome editing method CRISPR/Cas9, showed that both mutations confer significant levels of resistance: the I to M mutation results in a Resistance Ratio $>2,900$ folds and the $\mathrm{I}$ to $\mathrm{L}$ mutation $>20$ folds (operational significant levels of resistance) (Douris et al. 2016; Grigoraki et al. 2017).

The presence, frequency and geographical distribution of DFB resistance mutations in $C x$. pipiens populations from Northern Italy, where DFB is used intensively and resistance was first detected (Grigoraki et al. 2017) and in populations from other regions such as Greece and France remain largely unknown, albeit they have important implications in mosquito control strategies (Grigoraki et al. 2017).

In this study, we monitored the geographic distribution and frequency of the chitin synthase mutations in Northern Italy(in the Emilia-Romagna region, where the resistance was firstly detected), and in populations from Greece and France, and ACCEPTED assessedthepotentialcorrelationsbetween presence and frequency of resistance mutations with the history of FB applications.

\section{Materials and Methods}

\subsection{Study regions, field sample collections and mosquito handling}

$x$. pipiens collections were conducted in selected sites in Italy, Greece and France, based on the presence of prolific $C x$. pipiens breeding sites, recent history of WNV transmission, diflubenzuron applications for vector and pest control and, for Italy, on the previous detection of DFB resistance.

In Northern Italy, Cx. pipiens samples were collected, during the summer of 2017, from thirty localities (treated as thirty populations) in urban and peri-urban 
areas of all nine Emilia-Romagna provinces: Piacenza, Parma, Reggio-Emilia, Modena (Western provinces), Bologna, Ferrara, Ravenna, Forli-Cesena, Rimini (Eastern provinces) (Supplementary Table 1). Larval samples were collected from at least five breeding sites in each locality, so as to reduce the probability of including isofemale mosquitoes in the resistance analysis. Mosquito larvae were identified morphologically to species (Schaffner et al. 2001) and stored in ethanol 90\%.

In Greece, $C x$. pipiens samples were collected from eight localities in three different regions: Thessaloniki, Evros (Northern Greece) and Attica (Central Greece). Adult samples were collected from four agricultural sites (rice fields) in Northern Greece; two in Thessaloniki and two in Evros, in 2014, with CDC light traps baited with dry ice. The Thessaloniki sites were surveyed again in 2017 with larvae dipping collections. In Attica, larvae dipping collections were conducted in four urban sites (two sites in 2015 and two sites in 2017). The $3^{\text {rd }}-4^{\text {th }}$ instar larvae and adult mosquitoes were identified morphologically to species (Schaffner et al. 2001) and stored in ethanol 90\%. A subset of larval samples collected from Thessaloniki and Attica in 2017 were included in WHO larvae susceptibility bioassays against DFB.

In France, larval samples were collected from Montpellier, identified to species (Schaffner et al. 2001) and stored in ethanol 90\%.

\subsection{WHO bioassays}

Standard WHO larval bioassays (WHO 2005) were performed using $3^{\text {rd }}-4^{\text {th }}$ instar $C x$. pipiens larvae sampled from Greece. Diflubenzuron (DEVICE SC-15, diflubenzuron 13.9\%, Arysta LifeScience, UK) doses tested ranged from 0.00015 to 1 ppm (dilutions made in water) (Grigoraki et al. 2017). 


\subsection{Detection of Diflubenzuron resistance mutations}

\subsubsection{DNA extraction}

Genomic DNA was extracted from single larvae and adults of $C x$. pipiens mosquitoes using the CethylTrymethyl Ammonium Bromide (CTAB) method (Navajas et al. 1999) and the DNAzol method (according to the manufacturer's instructions -

Invitrogen) respectively.

MANUSCRIPT

\subsubsection{Detection of mutation I1043L}

An allele specific PCR was used to identify individuals carrying the I1043L mutation (Grigoraki et al. 2017). The primers External F_(5'-GCAGTCCTTCGGCGATCTT3'),External_R(5'-GAACAGTCCGGCGATGGATA-3'),CTC F _ (5'GGCTTGATCTACCTGCTGTCTC-3') and ATC_R AACAGCAAGTACATAGACGGGAT-3') were combined in one reaction to amplify

a control band (External_F/External 352 bp band), the susceptible allele(ExternalF/ATCR135bpband)andtheresistantallele(CTCF/ExternalR60bp

band) respectively if present. The PCR conditions were initial denaturation for $5 \mathrm{~min}$ at $95^{\circ} \mathrm{C}$ followed by 28 cycles of $30 \mathrm{sec}$ at $95^{\circ} \mathrm{C}, 30 \mathrm{sec}$ at $68^{\circ} \mathrm{C}, 1 \mathrm{~min}$ at $72^{\circ} \mathrm{C}$ and a final extension of $5 \mathrm{~min}$ at $72^{\circ} \mathrm{C}$. PCR products were analyzed by electrophoresis on a $2 \%$ agarose gel. Samples of known genotype were included in the analysis as positive controls and reactions without DNA were included as negative controls.

\subsubsection{Detection of mutation I1043M}


The presence of the I1043M mutation was monitored with a PCR-RFLP diagnostic assay described in Grigoraki et al. (2017). A 124 bp fragment flanking the I1043 site was amplified using the primers I1043M_F (5'-GCCTGTCTCCATCCGCAAG-3') 
and I1043M_R (5'-CCCAGGAGACGACGTTCAG-3'). The PCR conditions were initial denaturation for $5 \mathrm{~min}$ at $95^{\circ} \mathrm{C}$ followed by 30 cycles of $30 \mathrm{sec}$ at $95^{\circ} \mathrm{C}, 30 \mathrm{sec}$ at $60^{\circ} \mathrm{C}, 30 \mathrm{sec}$ at $72^{\circ} \mathrm{C}$ and a final extension of $5 \mathrm{~min}$ at $72^{\circ} \mathrm{C}$. From the resulting PCR products $(25 \mu 1), 5 \mu 1$ were run on a $3 \%$ agarose gel to validate successful amplification. The remaining product was digested as described in Grigoraki et al. (2017) with $5 \mathrm{U}$ of the restriction enzyme NlaIII (Thermoscientific, Milan, Italy) for two hours at $37^{\circ} \mathrm{C}$. NlaIII selectively MANUSCRIPTcleavestheresistantallele1043Mproducing two diagnostic bands of 60 and $64 \mathrm{bp}$. The digestion products were fractionated on a 3\% agarose gel. Samples of known genotype were included as positive controls. Negative controls (i.e. reactions without PCR products) were also included.

\subsection{History of agricultural land use and Diflubenzuron applications}

Data for the agricultural land use and DFB applications in the study areas from ' 80 s to date was collected in order to assess potential correlations between presence and frequency of resistance mutations with the history of DFB applications. The data was obtained from the databases of the Statistical National Institute of Italy, (ISTAT, https://www.istat.it/), the database of the European Union EUROSTAT (https://ec.europa.eu/eurostat), and the bibliographic database Google Scholar (www.scholar.com) that allowed us to search for peer reviewed literature as well as other documents (i.e. articles, theses, books, reports). Search was done using the keywords: "diflubenzuron AND Emilia-Romagna" (i.e. the region name for Italy); "benzoylurea AND Emilia-Romagna"; Attica, Evros and Thessaloniki were used as region names for Greece, and Languedoc-Roussillon for France. The search was updated to the $20^{\text {th }}$ November 2018. The title and abstract of each document was scanned and, if relevant, the full text and bibliographic section of the document was studied. 


\section{Results}

\subsection{Detection of Diflubenzuron resistance mutations}

A total of 1605 Culex pipiens mosquitoes (1460 collected in Italy, 121 in Greece and 24 in France) were analysed individually for detection of the DFB resistant mutations I1043L and I1043M (Table 1, Supplementary Table 2).

populations. Within these sites, the mutation was detected at an allele frequency ranging from 4 to $60 \%$ with higher mutation frequencies recorded in populations from the Eastern provinces. The I1043M mutation was detected in 10 out of the 30

In Italy, the mutated allele I1043LMANUSCRIPTwasdetectedin20outofthe30Cx.pipiens

Western Provinces of the Emilia-Romagna region.

populations at an allele frequency ranging from 8 to $77.1 \%$ ( able 1). As depicted in Figure 1, this mutation was detected only in the Eastern provinces. Heterozygotes harbouring both mutations (I1043L/I1043M) were detected in 5 out the 30 populations with a genotype frequency ranging from 4 to $37.5 \%$. DFB resistant mutations were not detected in eight populations, all of which were sampled from the

Cx. pipiens populations from Thessaloniki and Attica (Greece) were tested with WHO larvae bioassays for their susceptibility to DFB. No adults emerged, indicating susceptibility to the insecticide. Twenty four $3^{\text {rd }}-4^{\text {th }}$ instar mosquito larvae (from a total of 280 larvae exposed to insecticide) survived the DFB bioassay diagnostic resistance dose for 10 days albeit not reaching the adult stage, by which time all control larvae (not exposed to insecticide) had emerged to adults. These survivors were included in the molecular analysis in order to test for possible incipient resistance (i.e. presence of mutations in an heterozygous form, at a very low 
frequency in the populations). All mosquitoes $(n=121)$ analyzed from Greece with the molecular diagnostic assays (including larvae survived the bioassay) were 
homozygous for the susceptible allele I1043 (Table 1). Similarly to Greece, no resistance mutations were detected in the $C x$. pipiens mosquitoes analysed from France (all samples were homozygous for the susceptible allele I1043) (Table 1).

\subsection{History of agricultural land use and Diflubenzuron applications}

A total of 292 documents were found in the statistical and bibliographic databases, 62 relevant to the history of agricultural land use and DFB applications in the study areas (Supplementary Table 3).

Differences between the Western and Eastern provinces of the EmiliaRomagna region (Italy), and between Italy, Greece and France were revealed in terms of the land use and DFB applications against agricultural pests and mosquitoes. In the Emilia-Romagna region, fruit production (i.e. apples, peaches, and apricots) represents one of the principal agricultural activities with approximately 100.000 hectares of orchards, mostly distributed in the Eastern provinces (Table 2) (https://www4.istat.it/it/censimento-agricoltura/agricoltura-2000). Chemical control has been the major strategy to control orchard pests and chitin inhibitors were largely used in orchards from the ' 80 s to 2000 s (benzylourea was one of the top-5 insecticide classes applied to fruit tree crops in Italy in the years 1992-2003) (Muthmann and Nardin 2007). DFB was largely employed in the Emilia-Romagna orchards, against leaf miners and leafroller moths (Baronio and Pasqualini 1984; Ioratti et al. 2000; Ioriatti et al. 2003), particularly in the Eastern provinces, where orchards were more extended than in the Western provinces (Table 2). After the detection of DFB resistance in orchard pests, its use in orchards was ceased in the early 2000s (Faccioli et al. 1990; Reyes et al. 2007; Ioratti et al. 2000; Butturini et al. 2006; Civolani 2012).

Regarding mosquito control, in the last 10-15 years DFB based products have been used intensively in urban areas of both Eastern and Western Emilia-Romagna provinces to control the mosquito Aedes albopictus in road drains, a larval habitat also 
exploited by $C x$. pipiens (Bellini et al. 2009; Talbalaghi et al. 2010). More specifically, from 2005 onwards an average of 4-6 DFB based treatments have been conducted per season for Ae. albopictus control throughout the Emilia-Romagna region (Emilia-Romagna Region, 2008).

Contrary to Italy, DFB may have been used to a lesser extend in Greece against agriculture pests. Rice and cotton are the major crops of the Thessaloniki and Evros regions, and crop pest control has been mainly implemented using pyrethroid insecticides (Sürek, 2001; Chaudhry, 1996; Lemonakis and Chatzioglou, 2002; Chaskopoulou et al., 2016). Mosquito control programs have been implemented in these regions since 1996 using Bacillus thuringiensis var. israelensis (Vectobac SL) in the natural environment, temephos (from 1996-2008) and diflubenzuron (from 2008-to the present) in rice fields and in urban and peri-urban breeding sites (Iatrou and Mourelatos 2007; Mourelatos et al. 2007; Piakis et al. 2007; Chaskopoulou et al. 2011; Kioulos et al. 2014). In the urban areas of Attica, mosquito control is implemented via household and outdoor pyrethroid spraying (Fotakis et al. 2017).

ACCEPTEDFinally,intheLanguedoc-Roussillon region (France), grapevine is the major crop, and DFB has never been used against crop pests and vector control (Abrantes et al. 2010). number of studies note the use of DFB against C. pomonella in apple orchards in some other regions in the $90 \mathrm{~s}$, and following the detection of DFB resistance, its use was abandoned (Leonard 2003; Reyes et al. 2007; Damos et al. 2015).

\section{Discussion}

The chitin synthase mutations I1043L and I1043M, associated with striking DFB resistance (Grigoraki et al. 2017), were detected in Cx. pipiens populations in Northern Italy, reaching very high allelic frequencies, over $70 \%$ in certain populations 
(Figure 1, Table 1). On the contrary, no mutations were detected in the Cx. pipiens samples from Greece and France.

The presence and distribution of DFB resistance mutations appear to be highly focal. Our results show that there is a clear pattern of increasing resistant allele frequencies moving from the Western Emilia-Romagna provinces, appearing largely susceptible to DFB, towards the Eastern provinces, appearing largely resistant to DFB (Figure 1, Table 1). Variation in the resistant allele frequencies is also evident between the Eastern provinces and within the different populations sampled from the same province. Furthermore, the mutation I1043M conferring $>15,000$-fold diflubenzuron resistance (compared to $\mathrm{I1043L}>20$ fold) (Douris et al. 2016) was detected only in the Eastern provinces (Figure 1, Table 1).

Focal distribution of insecticide resistance has been associated with the different selection regimes imposed on the mosquito populations (Nkya et al. 2013 and reference therein). The observed pattern of focal resistance can be resulted from the combination of intense DFB selection pressures, in the form of agricultural pest and mosquito control DFB applications. Given that nucleotide mutations are rare events (Ffrench-Constant 2013), it is unlike that the two mutations, first detected in Cx. pipiens mosquitoes in milia-Romagna (Grigoraki et al. 2017), originated in this region in the last 15 years (i.e. since the 2000s, when the mosquito control programmes started). On the contrary, it is highly likely that they were present long before the beginning of the mosquito control applications and persisted in the populations under a selective pressure (French-Constant 2013). The history of agriculture land use and DFB applications in the Emilia-Romagna provinces allow us to hypothesize that the orchard DFB applications could have acted as the initial selective pressure favouring the selection of the resistant alleles. 
More specifically, the DFB based agricultural pest control applications taking place in the Eastern provinces could have resulted in an initial selection for DFB resistance mutations in local $C x$. pipiens mosquitoes. DFB was used in the orchards of Western provinces with the same intensity than in the Eastern provinces, in terms of DFB dose/hectare and application frequency (Pasqualini and Civolani, 2002; Rodrigues et al. 2013). However, the significant higher orchard extension in the Eastern provinces most likely led to an increased DFB exposure and subsequent resistance selection pressure imposed on the $C x$. pipiens individuals/populations of the Eastern provinces, resulting in the selection for DFB resistant alleles and their persistence within the local populations. This initial selection was most probably further boosted by the selection pressure imposed by the mosquito control applications, resulting in the high mutation frequencies detected. Within one year (from 2015 to 2016) of approximately five DFB mosquito control applications, DFB resistance evolved in Cx. pipiens mosquitoes from RRLC50 $=32$ fold (in 2015) to RRLC50 $=128$-fold (in 2016) in Ravenna, Italy (Grigoraki et al. 2017). In the following year (2016-2017), under similar selection pressure overall mutation allelic frequency (including both mutations) in the Ravenna and Marina di Ravenna localities (sites 21, 22 , Figure 1, Table 2) reached a frequency of 70 and $95.8 \%$, respectively.

In the Western provinces, low to moderate initial selection pressure (less orchard extension and, therefore, less individuals/populations of $C x$. pipiens exposed to DFB), didn't allow resistant mutations, if present, to persist within the populations. In these provinces only the I1043L resistant allele was found in 2017. Gene flow and/or long distance human-driven transport from Eastern provinces could account for its presence and diffusion among Western localities (i.e. sites 1, 4, 8-10) (Figure 1, Table 1). Likewise, gene flow from neighbouring localities, where only susceptible alleles are present (i.e. sites 2, 3, 5-7) (Figure 1, Table 1), would dilute the I1043L 
allele which, despite the selection pressure generated from mosquito control applications, ranges from 0.0 to $12.8 \%$. Future genetic population studies aiming to investigate the patterns of gene flow among $C x$. pipiens populations could allow us to shed light on the diffusion of the resistant alleles across the Emilia-Romagna region. Likewise, future studies about possible fitness costs of the resistant alleles could help to assess the relative role of the selective advantage and gene flow in shaping their current frequency and distribution in the region.

Contrary to Italy, DFB resistance was not detected in the $C x$. pipiens mosquitoes sampled from Greece and France (Table 1). This may be attributed to the different selection pressures imposed on these populations; DFB may have been used to a lesser extent in agricultural pest in both countries compared to Italy thus resulting in a possibly reduced selection for DFB resistance (Piakis et al. 2007; Kioulos et al. 2014; Lundström 2017; Muthmann and Nardin 2007). onetheless, further monitoring over space and time is required in order to gain a clear picture of the $C x$. pipiens DFB resistance status in Greece and France and support evidence based control.

In all, it can be hypothesized that the combination of both DFB selection pressures (intense agricultural FB applications followed by mosquito control DFB applications) resulted in the high mutation frequencies recorded in the $C x$. pipiens populations of the Eastern provinces in Emilia-Romagna. However, where the former pressure (agricultural applications) is low to moderate (Western provinces, Italy) DFB resistant mutation frequencies are low despite mosquito control. Among possible reasons why agricultural spraying may have an important impact in vector control, are the very high insecticide dosages used in agricultural applications compared to vector control: for example, the recommended dose of an agricultural formulation of diflubenzuron is up to $739 \mathrm{~g}$ of $\mathrm{DFB} /$ hectare, whereas the recommended dose for mosquito control does not exceed the $99 \mathrm{~g}$ of DFB/hectare. 
Our results are of major concern for public health in Italy and Europe. DFB remains indeed a very important insecticide used for controlling arbovirus mosquito vectors, where alternative larvicides are extremely limited. The insurgence of DFB resistance in $C x$. pipiens populations in the Eastern Emilia-Romagna provinces, the high mutation frequencies recorded, the high potential for augmentation of the resistant allele frequencies in the Western provinces upon the current insecticide

regime (DFB based mosquito control) MANUSCRIPTandthelimitednumberofavailablelarvicides

highlight the necessity for the development of appropriate Insecticide Resistance

Management (IRM) programs in these settings, to ensure the sustainability of current control interventions and safeguard public health. Although the fitness costs of the DFB resistant mutations I1043L and 1043M in the chs gene remain unknown, rotating between other available larviciding active ingredients as well as incorporating other vector control methodologies in parallel to larviciding could help in managing the current situation. However the potential development of multiple resistance should not be left un-adressed and requires investigation. In the Emilia-Romagna region, resistance to organophosphate insecticides was documented in $C x$. pipiens populations from Ravenna (resistance esterases A4/B4 and A5/B5) (Toma et al. 2011), There are no documented cases of resistance against pyrethroids in $C x$. pipiens mosquitoes in Northern Italy yet (Scott et al. 2015) A recent study on Aedes albopictus mosquitoes detected pyrethroid resistance mutations (Pichler et al. 2018) in populations from the Emilia-Romagna region raising concerns regarding the development of pyrethroid resistance in other mosquito species including Culex pipiens. Finally, ongoing $C x$. pipiens resistance surveillance in Northern Italy and other regions of the country where DFB applications take place, including the monitoring of other vector species such as Aedes albopictus for DFB resistance mutations are prerequisites for the 
development and execution of IRM strategies resulting in efficient and effective arbovirus vector control.

\section{Conclusions}

An understanding of the environmental factors affecting the response of insect pests to insecticides is pivotal to better manage resistance. Here we showed that the selection pressures from intense agricultural DFB applications, followed by mosquito control DFB applications, can account for the high mutation frequencies observed in the $C x$. pipiens populations of the Eastern provinces in the Emilia-Romagna region in Italy. Monitoring of mosquito vectors for possible insecticide resistant alleles in multiple geographical regions and environmental settings is needed for the development of appropriate IRM strategies and public health protection.

\section{Acknowledgements}

This study has been performed thanks to a specific financial support from the Regional Health Authority of Emilia-Romagna. We thank the Editor and two Reviewers for the work done on our manuscript, Edison Pasqualini and Stefano Maini of the Department of Agro-Alimentary Science and Technology (DISTAL), University of Bologna for the kind help in the analysis and understanding of agricultural aspects; Valentina Lucchesi and Alessandra Spanò for technical support. E.A. F. was supported by the General Secretariat for Research and Technology (GSRT) and the Hellenic Foundation for Research and Innovation (HFRI) in the context of the action "1st Proclamation of Scholarships from ELIDEK for PhD Candidates" (Scholarship Code: 532). 


\section{References}

- Abrantes, P., Christophe, S., Jarrige, F., Laurens, L., 2010. Dynamiques urbaines et mutations des espaces agricoles en Languedoc-Roussillon (France). Cybergeo 485.

\section{MANUSCRIPT}

- Balenghien, T., et al., 2008. Vector competence of some French Culex and Aedes mosquitoes for West Nile virus. Vector Borne Zoonotic Dis. 8(5), 58995.

- Baronio, P., Pasqualini, E., 1984. Diflubenzuron. La Difesa delle Piante. 7(2), 1141.

- Bellini, R., et al., 2009. Efficacy and lasting activity of four IGRs formulations against mosquitoes in catch basins of northern Italy. Eur. Mosq. Bull. 27, 33-46.

- Bellini, R, Zeller, H., Van Bortel, W., 2014.review of the vector management methods to prevent and control outbreaks of West Nile virus infection and the

ACCEPTEDchallengeforEurope.Parasit.Vectors. 7, 323.

- Becker, N., et al., 2010. Mosquitoes and Their Control, Springer, Berlin.

- Becker, N., Lüthy, P., 2017. Mosquito control with entomopathogenic bacteria in urope, in: Lacey, L., (Ed.), Microbial Control of Insect and Mite Pests, Elsevier, Netherlands, pp. 379-390.

- Butturini, ., Caroli, L., Boselli, M., Fagioli, L., 2006. Monitoraggio della resistenza di Cydia pomonella agli insetticidi in Emilia-Romagna: test laboratorio e prove di campo. ATTI Giornate Fitopatologiche, I, 29-36.

- Chaskopoulou, A., et al., 2011. Evidence of enzootic circulation of West Nile virus (Nea Santa-Greece-2010, lineage 2), Greece, May to July 2011 Euro Surveill 16:pii:19933. 
- Chaskopoulou, A., et al., 2013. Detection and early warning of West Nile Virus circulation in central Macedonia, Greece, using sentinel chickens and mosquitoes. Vector-Borne Zoonotic Dis., 13, 723-732.

- Chaskopoulou, et al., 2016. Ecology of West Nile virus across four European countries: review of weather profiles, vector population dynamics and vector control response. Parasit. Vectors, 9, 482.

- Chaudhry, M., 1996. Trends MANUSCRIPTinagrochemicalsusedtogrowcotton.In:

Seminar on International Commodity-Related Environmental Agreements as an Instrument for Sustainable Development. Netherlands. 23 February, 1996. https://www.icac.org/cotton_info/speeches/Chaudhry/rcnetherlands96.PDF.

- Civolani, S., 2012. The past and present of pear protection against the pear psylla, Cacopsylla pyri L. Insecticides - Pest Engineering. INTECH Open Access Publisher, 385-408.

- Damos, P., Colomar, L.A.E., Ioratti, ., 2015. Integrated Fruit Production and Pest Management in Europe: The Apple Case Study and How Far We Are From the Original Concept? Insects 6(3), 626-657.

- Douris, V., et al., 2016. Resistance mutation conserved between insects and mites unravels the benzoylurea insecticide mode of action on chitin biosynthesis. roc. Natl. Acad. Sci. USA, 113,14692-14697.

ECDC ( uropean Centre for Disease Prevention and Control) 2017, https://ecdc.europa.eu/en/west-nile-fever/surveillance-and-diseasedata/disease-data-ecdc.

(accessed $20^{\text {th }}$ Novembre 2018).

ECDC (European Centre for Disease Prevention and Control) 2018, https://ecdc.europa.eu/en/news-events/epidemiological-update-west-nile-virustransmission-season-europe-2017 
(accessed $20^{\text {th }}$ Novembre 2018).

Emilia-Romagna Region, 2008. Deliberazione n. 380 del 3 marzo 2008.

https://salute.regione.emilia-romagna.it/documentazione/leggi/regionali/dgr-

2127-2016/programmazione-provvedimenti-regionali-del-2008/dgr-280-2008/

(accessed $20^{\text {th }}$ Novembre 2018).

- Faccioli, G., et al, 1990. Evaluation of the efficacy of some insecticides against Leucoptera malifoliella MANUSCRIPTonappleinEmilia-

Romagna.Informatore Agrario 46, 93-96.

- Feyereisen, R., Dermauw, W., Van Leeuwen, ., 2015. Genotype to phenotype, the molecular and physiological dimensions of resistance in arthropods. Pest Biochem. Physiol. 121, 1-17.

- Ffrench-Constant, R.H., 2013. The molecular genetics of insecticide resistance. Genetics. 194, 807-15.

- Fotakis, E.A., et al. 2017. Analysis of population structure and insecticide resistance in mosquitoes of the genus Culex, Anopheles and Aedes from different environments of Greece with a history of mosquito borne disease transmission. Acta Trop. 174, 29-37.

- Gomes, B., et al., 2013. Distribution and hybridization of Culex pipiens forms in Greece during the West Nile virus outbreak of 2010. Infect. Genet. Evol., $16,218-225$.

- Grigoraki, L., et al. 2017. Striking diflubenzuron resistance in Culex pipiens, the prime vector of West Nile Virus. Sci. Rep. 7(1), 11699.pmid:28916816.

- Iatrou, G., Mourelatos, S., 2007. Mosquito control in Greece. Int. Pest. Contr. 49(3), 66-69. 
- Ioriatti, C., Sauphanor, B., Cainelli, R., Rizzi, C., Tasin, M. 2000. Cydia pomonella L.: primo caso di resistenza a diflubenzuron in Trentino. Atti Giornate fitopatologiche 1, 319-326.

- Ioriatti, C., Bouvier, J.C., Butturini, A., Cornale, R., Tiso, R. 2003. Carpocapsa: la situazione della resistenza ad azinphos methyl e diflubenzuron in Trentino ed Emilia-Romagna. Informatore Fitopatologico 53(1), 53-60.

- Kioulos, I., Kampouraki, A., Morou, E., Skavdis, G., Vontas, J., 2014. Insecticide resistance status in the major West Nile virus vector Culex pipiens from Greece. Pest Manag. Sci. 70(4), 623-627.

- Lemonakis, N., Chatzioglou, F., 2002. Challenges Associated With Cotton Farming in Evros Region and How to Address Them. Dissertation. Alexandrio Technical Insitution of Thessaloniki, Department of Plant Production, Thessaloniki. Greece.

- Leonard, P. 2003. Managing Resistance for Sustainable Use of Plant Protection Products IRAC. http://citeseerx.ist.psu.edu/viewdoc/summary?doi=10.1.1.398.977 (accessed $20^{\text {th }}$ Novembre 2018).

- Liu, N.N., 2015. Insecticide resistance in mosquitoes: impact, mechanisms, and research directions. Ann. Rev. Entomol. 60, 537-59.

- Lundström, J. 2017. Vectors of mosquito-borne viruses and their control in Europe. Eur. J. Public Health 27, 3.

- Mavridis, K., et al., 2018. Detection of West Nile Virus - Lineage 2 in Culex pipiens 1 mosquitoes, associated with disease outbreak in Greece. Acta Trop. 182:64-68.

- Merzendorfer H., 2013. Chitin synthesis inhibitors: old molecole and new developments. Insect Sci. 20, 121-138 
- Möhlmann, T.W.R., et al., 2017. Community analysis of the abundance and diversity of mosquito species (Diptera: Culicidae) in three European countries at different latitudes. Parasit. Vectors 10, 510.

- Mourelatos, S., et al., 2007. Eight years of integrated mosquito control programs in Northern Greece: a successful example of applied ecology. J. Environ. Prot. Ecol. 7(3), 606-616.

- Muthmann, R., Nardin, P. 2007MANUSCRIPT.TheUseofPlantProtectionProductsinthe European Union: Data 1992-2003. Office for Official Publications of the European Communities, Luxembourg. https://ec.europa.eu/eurostat/web/products-statistical-books/-/KS-76-06669 (accessed $20^{\text {th }}$ Novembre 2018).

- Navajas, M., Lagnel, J., Fauvel, G., De Moraes, G., 1999. Sequence variation of ribosomal internal transcribed spacers (ITS) in commercially important phytoseiidae mites. Exp. Appl. Acarol. 23, 851-859.

- Nkya, T.E., Akhouaryri, I., Kisinza, W., David, J. ., 2013. Impact of ACCEPTEDenvironmentonmosquitoresponse to pyrethroid insecticides: facts, evidences and prospects. Insect Biochem. Mol. Biol. 43, 407-416.

- Pasqualini, E., Civolani, S., 2002. Mimic-Confirm (a.i. Tebufenozide): a tool for a soft and ecologically sound pest control in pear orchards. Bulletin IOBC/wprs, 25(11), 97-106.

- Paz, S., Semenza, J. ., 2013. Environmental drivers of West Nile fever epidemiology in Europe and Western Asia - a review. Int. J. Environ. Res. Public Health 10(8), 3543-62.

- Piakis, N., Iatrou, G., Mourelatos, S., Geweher, S., 2007. Five years of mosquito control in Northern Greece, in: Vreysen, M.J.B., Robinson, A.S., Hendrichs, J. (Eds), Area-Wide Control of Insect Pests: From Research to 
Field Implementation, Springer Science \& Business Media, Germany, pp. 699709.

- Pichler, V., et al., 2018. First evidence of resistance to pyrethroid insecticides in Italian Aedes albopictus populations 26 years after invasion. Pest Manag. Sci. 74, 1319-1327.

- Rath, S., Friedlander, L.G., Reuss, R. 2015. Diflubenzuron in: Residue Evaluation of Certain Veterinary Drugs. Joint FAO/WHO Expert Committee on Food Additives (JECFA),

81stMANUSCRIPTmeeting2015.FAOJECFAMonographs 18.

- Reyes, M., et al., 2007. Diversity of insecticide resistance mechanisms and spectrum in European populations of the Codling moth, Cydia pomonella. Pest Manag. Sci. 63, 890-902.

- Rizzo, C., et al., 2016. West Nile virus transmission: results from the integrated surveillance system in Italy, 2008 to 2015. Euro Surveill. 21(37), pii $=30340$.

- Rodrigues, A.R.S., Torres, J.B., Siqueira, H. . , Lacerda, D.P.A., 2013. Inheritance of lambda-cyhalothrin resistance in the predator lady beetle Eriopis connexa (Germar) (Coleoptera: Coccinellidae). Biol. Control. 64, 217224.

- Schaffner, F., et al., 2001. The mosquitoes of Europe/Les moustiques d'Europe. Logiciel d'identification et d'enseignement (CD-Rom). IRD Editions \& EID MeÂditerrane Âe, Montpellier, France.

- Scott, J.G., Yoshimizu, M.H., Kasai, S., 2015. Pyrethroid resistance in Culex pipiens mosquitoes. Pestic. Biochem. Physiol., 120, 68-76.

- Sürek, H., 2001. Rice cultural practice in Turkey [On-line]. In: Chataigner, J. (Ed.), The New Development in Rice Agronomy and Its Effects on Yield and 
Quality in Mediterranean Areas. CIHEAM, Montpellier (Available). http://om.ciheam.org/om/pdf/c58/03400067.pdf.

- Talbalaghi, A., Moutailler S., Vazeille, M., Failloux, A.B., 2010. Are Aedes albopictus or other mosquito species from northern Italy competent to sustain new arboviral outbreaks? Med. Vet. Entomol. 24, 83-87.

- Toma, L., et al., 2011. Status of insecticide resistance in Culex pipiens field populations from northeastern areas of Italy before the withdrawal of OP compounds. Pest Manag. Sci. 67, 100-106.

- Waldner, W., 1993. Rückblick und Vorschau auf die Bekämpfung des Apfelwicklers. Obstbau-Weinbau, 12: 355-357.

- World Health Organization: Guidelines for Laboratory and Field Testing of Mosquito Larvicides. Communicable Disease Control, Prevention and Eradication, WHO Pesticide Evaluation Scheme. Geneva: WHO; 2005. WHO/CDS/WHOPES/GCDPP/2005.13.

- WHO, 2014. A global brief on vector-borne diseases. WHO/DCO/WHD/2014.1 


\section{Figure Legend}

Figure 1. Chitin Synthase - 1043 genotype relative frequencies recorded in Culex pipiens populations from the Emilia-Romagna provinces, Italy. II = I1043/I1043 homozygous susceptible (in grey); IL = I1043/I1043L heterozygote (in yellow); LL = I1043L/I1043L homozygous mutant (in brown); IM = I1043/I1043M heterozygote (in orange) MM = I1043M/I1043M homozygous mutant (in red); LM = I1043L/I1043M heterozygous mutant (in pink). Numbers (1-30): codes corresponding to the different populations analyzed (see Table 1).

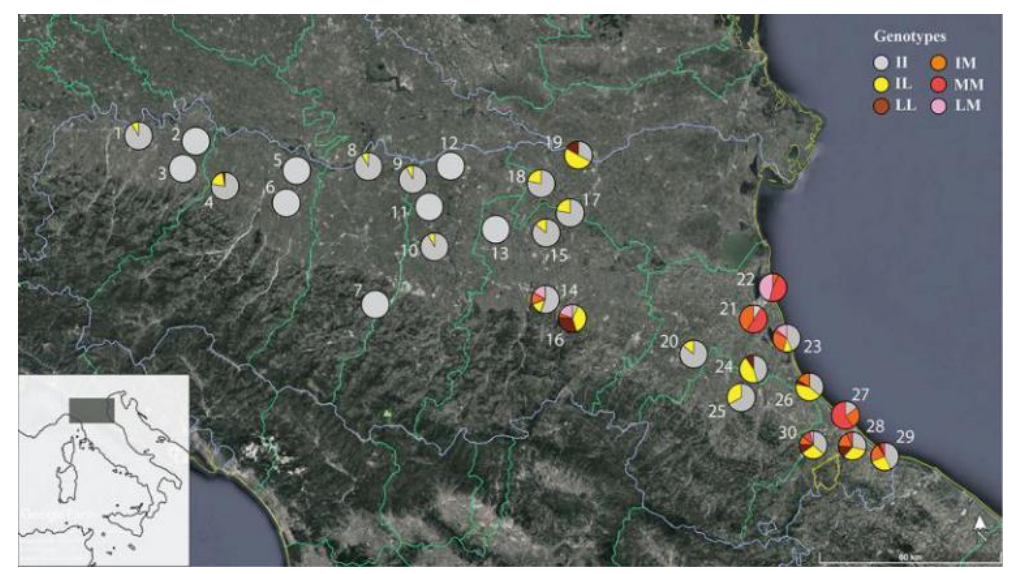


Table 1. Chitin Synthase - 1043 genotype and allele frequency in Culex pipiens populations from Italy, Greece and France. Codes (1-30) correspond to the samples analyzed from Italy; (31-35): samples from Greece. (36): France. For Italian samples, the provinces of the Emilia-Romagna region are shown in brackets: PC, Piacenza; PR, Parma; RE, Reggio-Emilia; MO, Modena; BO, Bologna; FE, Ferrara; RA, Ravenna; FC, Forlì-Cesena; RN, Rimini. For Greek samples, samples from the same region are 9. Guastalla (RE) $\quad 50 \quad 92.0 \quad$ MANUSCRIPT8.0------96.04.0-grouped together, population break down in supplementary able 2. GR: Greece; FR: France.

\begin{tabular}{|c|c|c|c|c|c|c|c|c|c|c|c|}
\hline \multirow[t]{2}{*}{ Code } & \multirow[t]{2}{*}{ Population } & \multirow[t]{2}{*}{$\mathbf{N}$} & \multicolumn{6}{|c|}{1043 Genotype (\%) } & \multicolumn{3}{|c|}{1043 Allele (\%) } \\
\hline & & & (II) & (IL) & (IM) & $(\mathbf{L L})$ & (MM) & (LM) & (I) & (L) & (M) \\
\hline 1. & Piacenza (PC) & 50 & 90.0 & 10.0 & -- & $\overline{--}$ & -- & -- & 95.0 & 5.0 & -- \\
\hline 2. & Cortemaggiore (PC) & 50 & 100.0 & -- & -- & -- & -- & -- & 100.0 & -- & -- \\
\hline 3. & Fiorenzuola (PC) & 50 & 100.0 & -- & -- & -- & -- & -- & 100.0 & -- & -- \\
\hline 4. & Fidenza (PR) & 47 & 76.6 & 21.3 & -- & 2.1 & -- & -- & 87.2 & 12.8 & -- \\
\hline 5. & Colorno (PR) & 50 & 100.0 & -- & -- & -- & -- & -- & 100.0 & -- & -- \\
\hline 6. & Parma (PR) & 48 & 100.0 & -- & -- & -- & -- & -- & 100.0 & -- & -- \\
\hline 7. & Castellarano di Reggio (RE) & 48 & 100.0 & -- & -- & -- & -- & -- & 100.0 & -- & -- \\
\hline 8. & Rolo (RE) & 49 & 89.8 & 10.2 & -- & -- & -- & -- & 94.9 & 5.1 & -- \\
\hline 10. & Modena (MO) & 47 & 91.5 & 8.5 & -- & -- & -- & -- & 95.7 & 4.3 & -- \\
\hline 11. & Carpi (MO) & 50 & 100.0 & -- & -- & -- & -- & -- & 100.0 & -- & -- \\
\hline 12. & Concordia (MO) & 45 & 100.0 & -- & -- & -- & -- & -- & 100.0 & -- & -- \\
\hline 13. & Crevalcore (BO) & 50 & 100.0 & -- & -- & -- & -- & -- & 100.0 & -- & -- \\
\hline 14. & Bologna (BO) & 48 & 54.2 & 14.6 & 14.6 & -- & -- & 16.7 & 68.8 & 15.6 & 15.6 \\
\hline 15. & S. Pietro in Casale (BO) & 49 & 87.7 & 12.3 & -- & -- & -- & -- & 93.9 & 6.1 & -- \\
\hline 16. & San Lazzaro (BO) & 50 & 6.0 & 40.0 & 4.0 & 30.0 & -- & 20.0 & 28.0 & 60.0 & 12.0 \\
\hline 17. & Poggio Renatico (FE) & 47 & 76.6 & 23.4 & -- & -- & -- & -- & 88.3 & 11.7 & -- \\
\hline 18. & Casumaro, Cento (FE) & 49 & 77.5 & 22.5 & -- & -- & -- & -- & 88.8 & 11.2 & -- \\
\hline 19. & Mizzana (FE) & 50 & 34.0 & 50.0 & -- & 16.0 & -- & -- & 59.0 & 41.0 & -- \\
\hline 20. & Faenza (RA) & 47 & 87.2 & 12.8 & -- & -- & -- & -- & 93.6 & 6.4 & -- \\
\hline 21. & Ravenna (RA) & 50 & 10.0 & -- & 40.0 & -- & 50.0 & -- & 30.0 & -- & 70.0 \\
\hline 22. & Marina di Ravenna (RA) & 48 & -- & -- & 8.3 & -- & 54.2 & 37.5 & 4.2 & 18.7 & 77.1 \\
\hline 23. & Cervia (RA) & 50 & 44.0 & 12.0 & 28.0 & -- & 4.0 & 12.0 & 64.0 & 18.0 & 18.0 \\
\hline
\end{tabular}




\begin{tabular}{|c|c|c|c|c|c|c|c|c|c|c|c|}
\hline 24. & Pievequinta (FC) & 50 & $46.0=$ & 44.0 & (1) ] & 10.0 & ใน & $\sqrt{2}$ & 68.0 & 32.0 & ]" \\
\hline 25. & Forlimpopoli (FC) & 48 & 68.5 & 31.5 & -- & -- & -- & -- & 84.4 & 15.6 & -- \\
\hline 26. & Cesenatico (FC) & 50 & 36.0 & 44.0 & 16.0 & 4.0 & -- & -- & 66.0 & 26.0 & 8.0 \\
\hline 27. & Rimini, Viale Avisio (RN) & 48 & 14.6 & -- & 29.2 & -- & 56.3 & -- & 29.2 & -- & 70.8 \\
\hline 28. & Rimini (RN) & 45 & 28.9 & 31.1 & 17.8 & 15.5 & 6.7 & -- & 52.2 & 30.4 & 17.4 \\
\hline 29. & Riccione (RN) & 47 & 42.6 & 25.5 & 21.2 & 4.3 & 6.4 & -- & 66.0 & 17.0 & 17.0 \\
\hline 30. & Santarcangelo (RN) & 50 & 36.0 & 30.0 & 10.0 & 10.0 & 10.0 & 4.0 & 56.0 & 27.0 & 17.0 \\
\hline 31. & Evros (GR) & 25 & 100.0 & -- & -- & -- & -- & -- & 100.0 & -- & -- \\
\hline 32. & Thessaloniki (GR) & 31 & 100.0 & -- & -- & -- & -- & -- & 100.0 & -- & -- \\
\hline 33. & Thessaloniki* (GR) & 9 & 100.0 & -- & -- & -- & -- & -- & 100.0 & -- & -- \\
\hline 34. & Attica (GR) & 41 & 100.0 & -- & -- & -- & -- & -- & 100.0 & -- & -- \\
\hline 35. & Attica* (GR) & 15 & 100.0 & -- & -- & -- & -- & -- & 100.0 & -- & -- \\
\hline 36. & Montpellier (FR) & 24 & 100.0 & -- & -- & -- & -- & -- & 100.0 & -- & -- \\
\hline
\end{tabular}

(II)=I1043/I1043 homozygous susceptible; (IL)=I1043/I1043L heterozygote; (LL)=I1043L/I1043L homozygous mutant; (IM)=I1043/I1043M heterozygote; $(\mathrm{MM})=\mathrm{I} 1043 \mathrm{M} / \mathrm{I} 1043 \mathrm{M}$ homozygous mutant; (LM)=I1043L/I1043M heterozygous mutant, $(\mathrm{I})=\mathrm{I} 1043$ susceptible allele, $(\mathrm{L})=1043 \mathrm{~L}$ mutant allele, $(\mathrm{M})=1043 \mathrm{M}$ mutant allele, $\mathrm{N}=$ number of individuals analyzed per population, $(\%)=$ frequency. $*$ WHO Bioassay survivors. 
Table 2. Extension of orchards and Diflubenzuron use against orchard pests and mosquitoes in the study areas.

\begin{tabular}{|c|c|c|c|c|c|c|}
\hline \multirow[t]{3}{*}{ Study areas } & \multirow{2}{*}{\multicolumn{2}{|c|}{$\begin{array}{c}\text { Orchard extensions } \\
\text { (hectares, mean } \pm \text { sd) } \\
1982-2000\end{array}$}} & \multicolumn{4}{|c|}{ Selection for Diflubenzuron resistance } \\
\hline & & & \multicolumn{2}{|c|}{ '80s-'90s } & \multicolumn{2}{|c|}{ since 2000s } \\
\hline & & & $\begin{array}{l}\text { pressure from } \\
\text { orchard pest } \\
\text { control* }^{*}\end{array}$ & $\begin{array}{l}\text { pressure from } \\
\text { mosquito } \\
\text { control^ }^{\wedge}\end{array}$ & $\begin{array}{l}\text { pressure from } \\
\text { orchard pest } \\
\text { control* }\end{array}$ & $\begin{array}{c}\text { pressure from } \\
\text { mosquito control}^{\wedge}\end{array}$ \\
\hline \multicolumn{7}{|l|}{$\begin{array}{l}\text { Emilia-Romagna } \\
\text { (Italy) }\end{array}$} \\
\hline Piacenza (w) & 703 & $( \pm 172)$ & + & - & - & + \\
\hline Parma (w) & 581 & $( \pm 323)$ & + & - & - & + \\
\hline Reggio-Emilia (w) & 1681 & $( \pm 373)$ & + & - & - & + \\
\hline Modena (w) & 11329 & $( \pm 327)$ & ++ & - & - & + \\
\hline Bologna (e) & 18038 & $( \pm 3206)$ & +++ & - & - & + \\
\hline Ferrara (e) & 22976 & $( \pm 3870)$ & +++ & - & - & + \\
\hline Ravenna (e) & 26164 & $( \pm 3359)$ & +++ & - & - & + \\
\hline Forlì-Cesena (e) & 15828 & $( \pm 1516)$ & +++ & - & - & + \\
\hline Rimini (e) & 947 & $( \pm 248)$ & + & - & - & + \\
\hline
\end{tabular}

(w) stands for western provinces, (e) for eastern provinces. The symbols "“-" and "+" refer to the different relative selection for Diflubenzuron resistance among the localities.

*^ Two distinctive relative pressure classifications (not comparable between them): * columns referring to relative pressure from orchard pest control: "_" no selective pressure; "+" light; "++" moderate; "+++" heavy.

$\wedge$ referring to relative pressure from mosquito control: "_" no treatments; "“+" refers to an average of 4-6 DFB based treatments per season (Emilia-Romagna Region, 2008). 